\title{
Morphodynamic study of the Ondarreta Beach in San Sebastian (Spain)
}

\author{
P. Liria, P. Gyssels, I. Galparsoro, Z. Santiago, M. Gonzalez \\ \& A. Uriarte \\ Marine Research Division, AZTI Foundation, Spain
}

\begin{abstract}
Ondarreta Beach is one of the most emblematic and visited beaches in the Basque Country. This beach is part of La Concha bay, with Santa Clara Island in the middle of the bay and a semi submerged dike and reef in front of it. The combination of this morphology together with the tidal range in the area (max. springs $4.6 \mathrm{~m}$ ) results in a very particular wave climate.

The beach contains different strata of sand, natural rocks and the remains of artificial structures. Therefore, rocks sometimes appear at the surface, depending on the changes of the beach profile. This situation harms the normal use of the beach and can be a risk for the users. During recent years this process has increased and, especially in the summer, a big part of the intertidal profile of the West part of the beach shows a gravely and rocky profile.

In 2003, the town council of San Sebastian entrusted AZTI Foundation with the study of this beach. For this purpose AZTI planned the data analysis and the morphodynamic study of the evolution of the beach in three different time scales, in order to clarify whether the recent problems at the beach are an increasing erosive process, or part of a natural cycle.

The three different time scales of analysis of morphodynamic processes taking place in this beach are:

- Short term scale: wave data measurement and analysis, modeling of wave, current and sediment transport.

- Medium term scale: analysis of seasonal equilibrium shape and profile.

- Long term scale: analysis of morphodynamic evolution of the whole system (the bay).

This analysis has contributed to the management of the beach, implying artificial seasonal sand movements, trying to encompass the natural processes and shoreline protection with the recreational use of the beach.

Keywords: morphodynamic, erosion, beach, management, wave modelling, short term, medium term, long term, recreational beach use.
\end{abstract}




\section{Introduction}

The study area is located in the south-eastern Bay of Biscay in the North coast of Spain (see Figure 1).

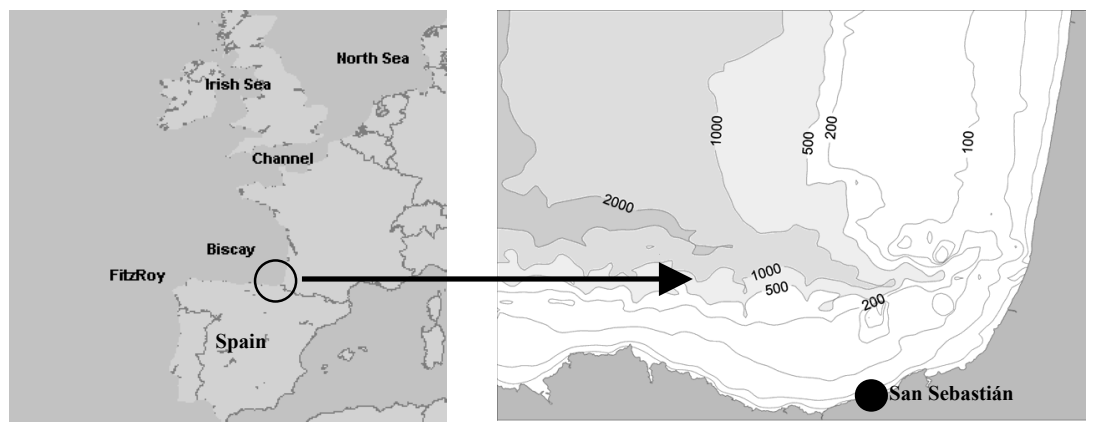

Figure 1: $\quad$ The location of the study area.

Ondarreta Beach is one of the most important reclaims for the tourism in the city of San Sebastian (North of Spain), during the summer months. This beach is sited in the west part of La Concha Bay, with Santa Clara Island in the middle of the bay and a semi submerged dike and reef in front of it (Figure 2).

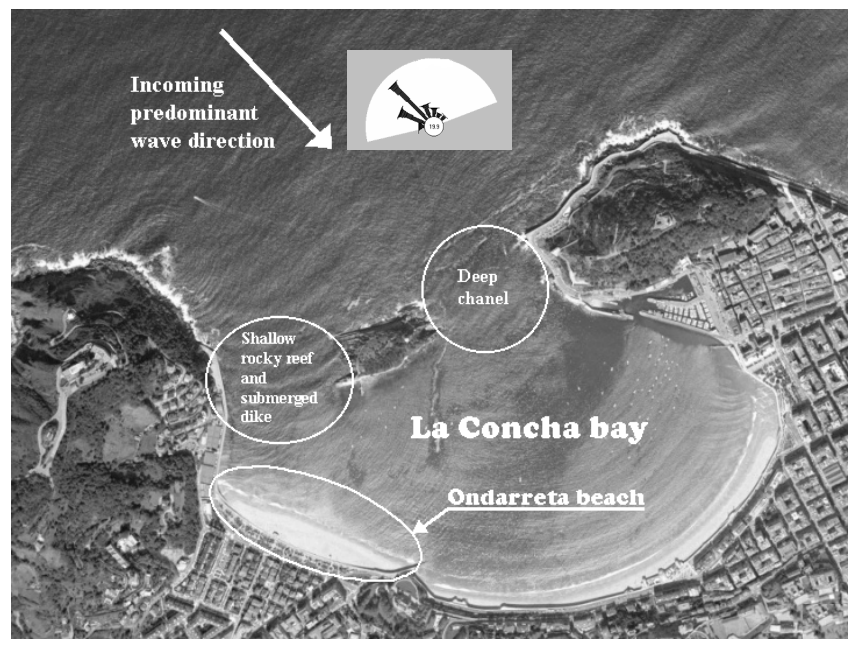

Figure 2: La Concha Bay.

The beach contains different strata of sand, natural rocks and remains of artificial structures. Therefore, rocks sometimes appear at the surface, depending on the changes of the beach profile (see Figure 3). 

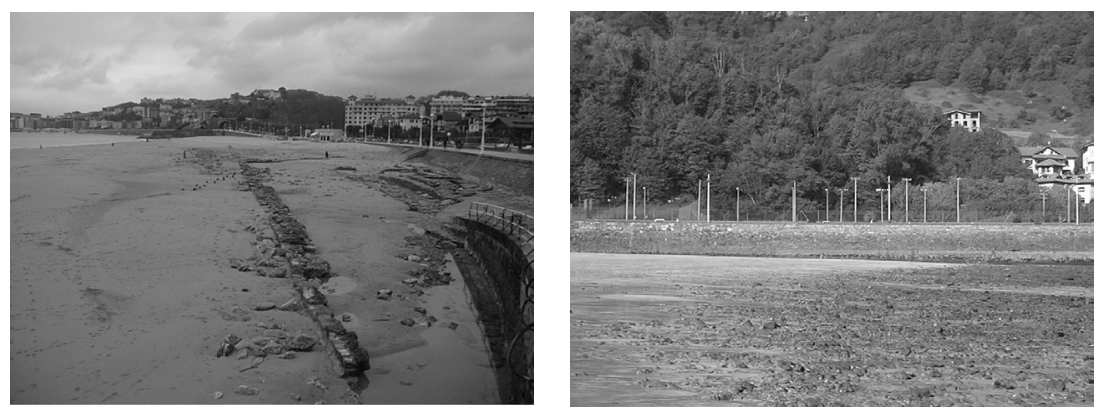

Figure 3: Gravel, rocks and remains of artificial structures at Ondarreta.

During the last years this process has increased especially during the summer seasons. Therefore in 2003 the town council of San Sebastian entrusted AZTI Foundation with the morphodynamic study of this beach.

\section{Morphodynamic study}

The study was undertaken between summer 2003 and summer of 2004. During the study two complete topographic, bathymetric, sediment analysis and acoustic seabed characterization campaigns were carried out, covering the whole of the bay. One of the surveys took place at the end of the summer of 2003 and another at the end of the winter of 2003-2004. The aim was to characterize the principal morphodynamic equilibrium states of the beaches.

There was another survey campaign during February of 2004, in order to record in situ wave data at Ondarreta beach.

\subsection{Beach characteristics}

Ondarreta is an urban beach, with a walk all along, finished with a vertical wall. It is $700 \mathrm{~m}$ long and $80 \mathrm{~m}$ wide (over high tide level in the wider part) and a higher elevation of around $7 \mathrm{~m}$ over spring low tide water level. On the West side, the beach finishes in a vertical wall named "Muro Del Tenis" and on its East side there are some rocks with a very particular form called "Pico Del Loro" that separate it from La Concha beach.

La Concha beach (Figure 2) is a semi circular shape beach of about $2 \mathrm{~km}$ long that continues the Ondarreta beach to the East. The rocks named "Pico Del Loro" only interrupt the emerged part of the beach but both La Concha and Ondarreta, are connected in the submerged part.

Ondarreta has well graded fine sand $\left(\mathrm{D}_{50}\right.$ around $\left.0.2 \mathrm{~mm}\right)$ that gets coarser in the East part.

Ondarreta has medium-low wave energy and a tidal range of between 2 and $4.6 \mathrm{~m}$. The beach profile is reflective, especially in the East part and during the summer, presenting a more dissipative profile at the West end of the beach. 


\subsection{Methodology and analysis}

In order to clarify, whether the recent problems of the beach are, related to an increasing erosive trend, or are part of a natural cycle, the study was planned at three different time scales.

Short term analysis is needed to understand the hydrodynamic of the area and to provide input data, to the longer time analysis models. Medium term analysis is used to characterize the seasonal medium equilibrium states and variations. Long term analysis helps understanding the evolution of the beach and to detect possible erosive problems.

\subsubsection{Short term}

Waves arrive to Ondarreta beach from two different sides because of its location. In addition wave size changes when the depth at both entrances of the bay varies during the tidal cycle. All this results in a very particular wave climate.

In this study short term analysis has two main aspects, wave modelling (propagation currents and sediment transport) and in situ wave measurements and analysis.

In this study the SMC (Coastal Modelling System) software has been used to simulate wave propagation, as well as induced currents and sediment transport. The SMC includes different documents and numerical implementation, to help with the coastal dynamics studies. It was developed by the Coastal Engineering and Oceanography Group (G.I.O.C.) from the University of Cantabria with the Coastal and Environmental Department of the Spanish Government.
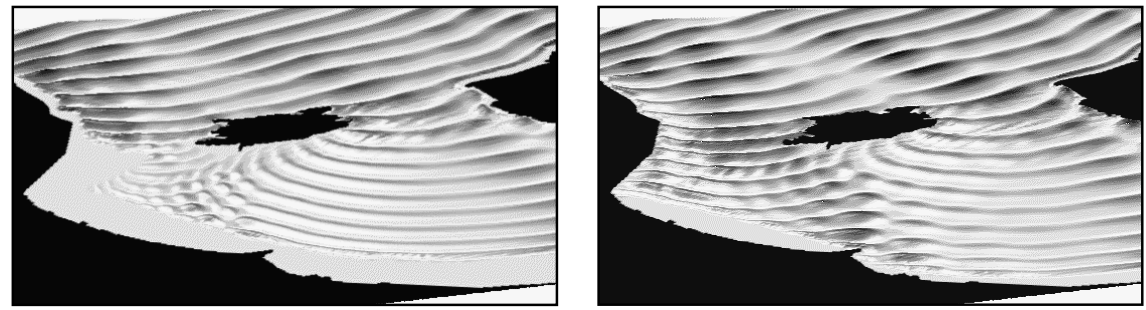

Figure 4: Monochromatic 3D view of wave propagation inside La Concha Bay, during low tide (left) and high tide (right).

This software uses the parabolic solution of the mild slope equations (MSP) (Kirby and Darlrymple [3]) for the wave propagation. The software allows the simulation of monochromatic or spectral waves from deep waters to the coast. In each case wave induced currents and potential sediment transport can be obtained.

In this study three different wave situations were characterized. A summer medium wave state, a winter medium wave state and an extreme storm (the largest within a return period of 5 years). Wave heights, currents and potential sediment transport were obtained in different states of the tide, in order to understand the principal hydrodynamic processes inside the Bay. 
Another important aspect was to obtain some in situ wave and currents measurements. During February of 2004 three Valeport instruments (waves, currents and turbidity) were situated in the breaking zone along Ondarreta beach and an S4 (waves, currents and tides) was situated at the west entrance of the bay.

Figure 5 shows medium water level (upper line) and wave height (lower line) during the in situ wave measurements campaign in February of 2004 at Ondarreta beach. This data correspond to the instrument situated at the west of the beach. The plot clearly shows how the wave height changes with the tide.

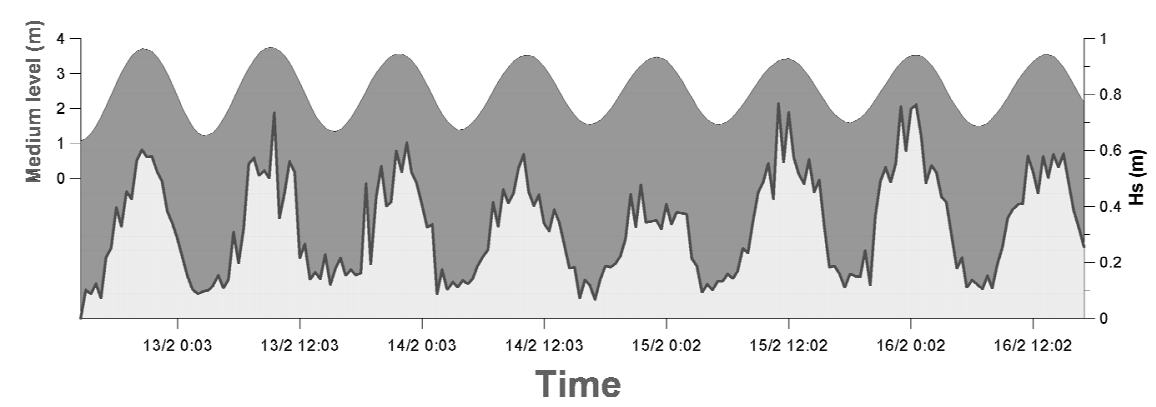

Figure 5: Wave height and medium water level at Ondarreta beach.

The data were used to calibrate the models. The same conditions of offshore wave characteristics taking place during the survey campaign, were simulated and compared with the results, selecting the optimum parameter combination to get the best match.

\subsubsection{Medium term}

La Concha Bay is located at the South-West end of the Bay of Biscay, in the North-East Atlantic. Therefore in terms of wave climate it has two different periods along the year. One from September to April, in which strong low pressure systems cross the North Atlantic from West to East, resulting in strong North-Westerly swells that hit the Atlantic coast of Europe. The other period goes from April to September when the permanent Azores high pressure system extends to the East, affecting Europe and the Bay of Biscay, providing good weather and predominant calm periods.

All this results in two principal medium states at beaches, with different predominant wave heights, wave periods and consequently, different morphology (Komar [4]).

During this study two complete topographic, bathymetric, sediment analysis and acoustic seabed characterisation campaigns were performed, covering the whole bay. One campaign was at the end of the summer of 2003 and another at the end of the winter of 2003-2004 in order to characterise the principal morphodynamic equilibrium states of the beaches (Wright et al. [7] and Short [5]). 
Along the beaches different control profiles were measured in both campaigns and Dean Profile was used $\left(h=A \cdot x^{2 / 3}\right)$ (Dean [1]) for adjustments.

Nine profiles were used at Ondarreta beach (O1 to O9 from West to East) and five at La Concha Beach (C1 to C5 from West to East)

Best fit was found in most of the cases by using two Dean Profiles. One for the intertidal part of the profile $\left(\mathrm{A}_{1}\right)$ and another for the submerged part $\left(\mathrm{A}_{2}\right)$ (Inman et al. [2]).

Table 1: Dean Parameter for the measured profiles during the winter and summer campaigns.

\begin{tabular}{|c|c|c|c|c|}
\hline \multirow{2}{*}{} & \multicolumn{2}{|c|}{ Summer } & \multicolumn{2}{c|}{ Winter } \\
\cline { 2 - 5 } & \multicolumn{2}{|c|}{$\mathrm{A}$} & $\mathrm{A}_{1}$ & $\mathrm{~A}_{2}$ \\
\hline $\mathrm{O} 1, \mathrm{O} 2$ & \multicolumn{2}{|c|}{0.15} & 0.08 & 0.2 \\
\hline O3, O4, O5, O6 & \multicolumn{2}{|c|}{0.21} & 0.08 & 0.375 \\
\hline O7, O8, O9 & \multicolumn{2}{|c|}{0.29} & 0.22 & 0.5 \\
\hline & $\mathrm{A}_{1}$ & $\mathrm{~A}_{2}$ & $\mathrm{~A}_{1}$ & $\mathrm{~A}_{2}$ \\
\hline $\mathrm{C} 1, \mathrm{C} 2, \mathrm{C} 3, \mathrm{C} 4, \mathrm{C} 5$ & 0.175 & 0.39 & 0.135 & 0.43 \\
\hline
\end{tabular}

In order to understand the main seasonal sand movements inside the Bay, data from the summer and winter topo-bathymetric campaigns data were compared (see Figure 6).

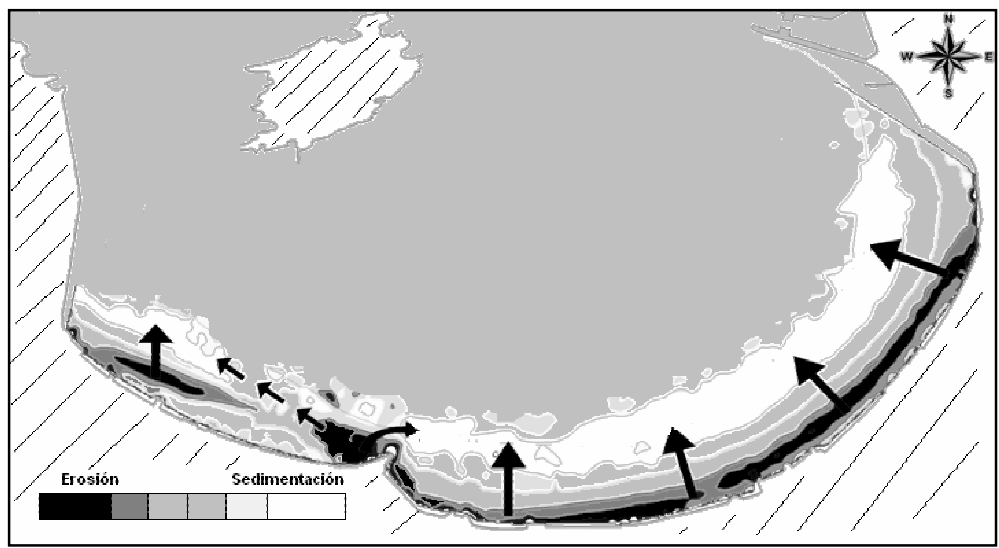

Figure 6: Principal seasonal sediment transport from summer to winter.

This analysis was done by using the difference in height between the summer and winter topo-bathymetric data, helped with the principal dynamics of each season (derived from the short term analysis). 


\subsubsection{Long term}

The shape of the beaches in the horizontal plane inside La Concha Bay is related to different diffraction points and reflective elements that change the predominant wave front direction along them. All of them result in a circular shape for La Concha beach centred in the middle of the East channel (Figure 7). Ondarreta Beach presents a rectilinear shape, with two predominant orientations. The East part is oriented to the waves coming from the east entrance of the bay, and the West part is faced towards the West entrance (Figure 7).

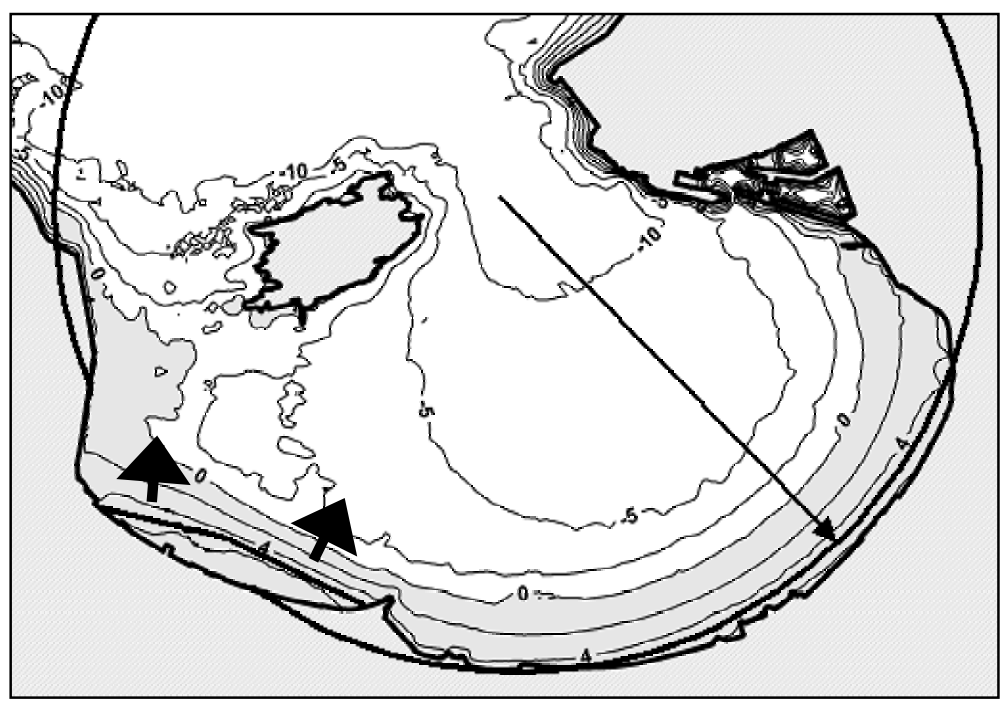

Figure 7: Equilibrium plant shape of the beaches.

Aerial photographs from 1954 (in this year the actual geometry of the artificial structures was already done) onwards were used to compare these forms and no remarkable changes were appreciated, apart from those derived from the seasonal predominant wave climate states.

Furthermore, the town council has been carrying out measurements of sand volumes, over the low tide limit, in both beaches every year at the beginning of the summer, since 1970. The analysis of the data set does not show any progressive sand loose at Ondarreta beach.

\subsection{Conclusions}

○ La Concha Bay is an enclosed system with minimum sediment interchange with the adjacent areas.

$\circ$ The sediment transport inside the Bay is predominantly dominated by wave induced dynamics. 
o The main sediment movements that affect the beaches are those derived from seasonal changes in the beach morphology in response to the predominant wave climate. This transport is predominantly perpendicular to the bathymetric contours.

o Sediment transport between Ondarreta and La Concha is reduced to seasonal profile changes around the zone named "Pico Del Loro".

$\circ$ The appearance of stones at the Ondarreta beach during summer is not caused by a progressive erosive problem.

o The appearance of stones at Ondarreta beach depends on the intensity of the seasonal sand movements in response to predominant wave climate.

\section{Recommendations for the Ondarreta Beach management.}

The West half of Ondarreta Beach has various strata of natural gravel as well as reminds of artificial structures covered with a relative thin layer of sand. During the last years stones have shown up at the surface very often, especially during summer, with the consequent effects to the recreational use of the beach.

This problem does not seem to be the result of a progressive erosive problem but the effect of the intensity of the seasonal natural sand movements along the last years.

Wave climate in the Bay of Biscay has two predominant states. Winter season goes from September to April with frequent storms and big swells. Summer is characterized by long calms and small sea waves.

During the winter beaches inside La Concha Bay, get more dissipative and in this process the predominant movement of sand goes from the upper part to the lower part. In this season Ondarreta beach presents, as shows in Figure 8, a small dry beach, and a long intertidal zone.

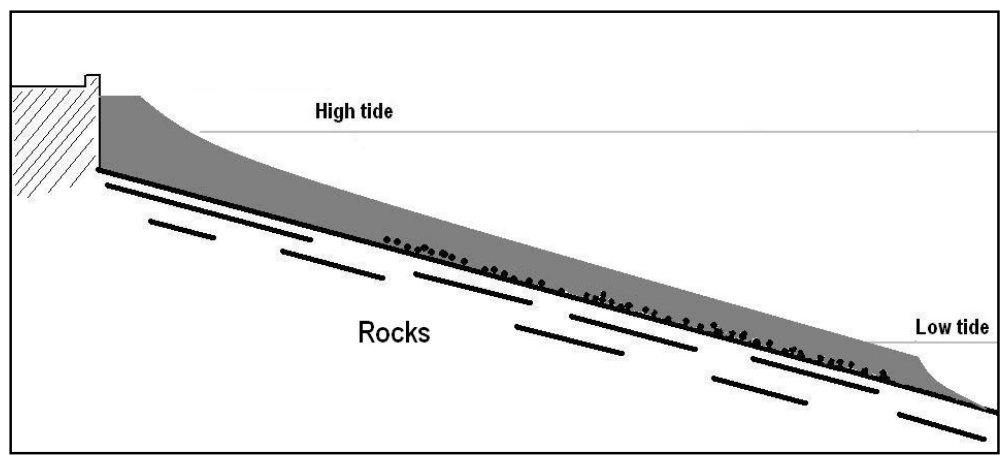

Figure 8: Typical beach configuration during the winter season at Ondarreta.

During the summer beaches inside La Concha Bay get more reflective: more vertical slopes and a tendency to an accretion of sand in the upper part of the beach. 
In the last few years a combination of mild winters with especially calm summers has produced an extra accumulation of sand in the upper part of Ondarreta beach. This process culminated in summer 2003 with an extra calm summer and a situation at the West part of Ondarreta as shown in Figure 9; a very large dry beach with an extra reflective profile and the lower half of the intertidal zone, showing gravel and the exposed rocky substrate. This situation worsens once grabs appear at the surface layers, since they can be easily moved by waves, affecting the whole profile.

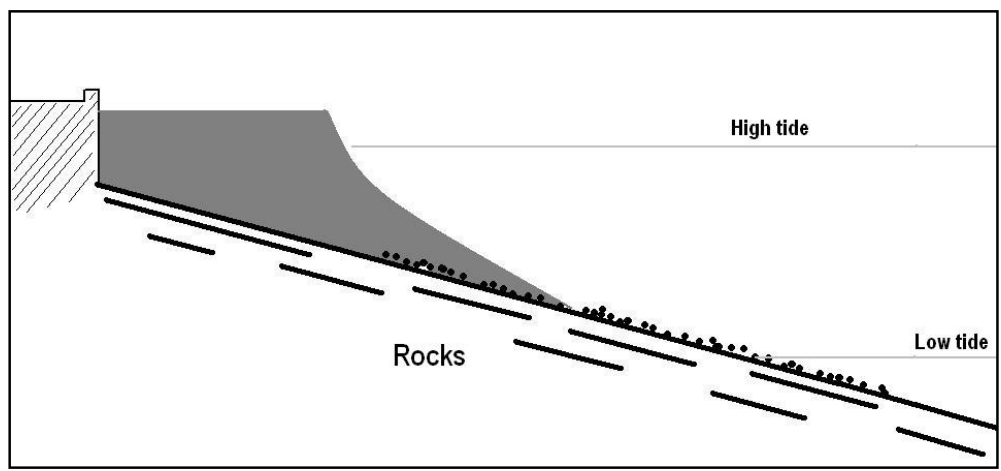

Figure 9: Beach configuration during summer 2003 at Ondarreta.

At the beginning of June 2004, the town council of San Sebastian asked for advice for summer restoration of the Ondarreta beach to AZTI Foundation. Some artificial movements of sand were done to mobilize the big accumulation of sand detected at the upper part of Ondarreta in the morphodynamic study. This has resulted in a better situation during summer of 2004 in spite of it being only a limited action of very small consequences.

As a conclusion, the best way of improving the recreational use of Ondarreta beach is to continue its monitoring, in order to get better knowledge of the morphodynamic processes and to be ready to work together with nature in achieving best results with minor environmental impact.

\section{References}

[1] Dean, R. G., (1977). Equilibrium beach profiles: U. S. Atlantic and Gulf coasts. Ocean eng. Dep. No. 12, dept. of Civil Eng., Univ. of Delaware, Nework, Del.

[2] Douglas L. Inman, M. Hany Elwany, Scott A. Jenkins, (1993). Shorerise and Bar-Berm Profiles on Ocean Beaches.

[3] Kirby, J. T., R. A. Darlrymple, (1983). A Parabolic Equation for the combined Refraction Diffraction of Stokes Waves by Mildy Varying Topography. J. Fluid Mech., 136, pp 543-566. 
[4] Komar, P.D., (1976) Beach processes and sedimentation. New Jersey: Pre. Hall, 429 pp.

[5] Short, A. D., (1979a). Wave power and beach stages: a global model. Conf. Coastal Engineering, 16th, pp. 1145-1162.

[6] Short, A. D., (1979b). Tree-dimensional beach stage model. Journal Geol. Vol 87, pp. 553-571.

[7] Wright, L.D., Chapel J., Tho., B.G., Bradinsaur, M.P., Cowell, P., (1979). Morphodymamics of reflective and dissipative beach and inshore systems. Southeast Australia. Marine Geology, Vol 32 pp. 105-140. 